\title{
Prevention of diabetes in Bangladeshis in East London: Experiences and views of young people
}

\author{
Shamsur R. Choudhury ${ }^{1}$, Amelia Furbish ${ }^{1}$, Tahseen A. Chowdhury ${ }^{2}$ \\ ${ }^{1}$ Healthwatch Tower Hamlets, Mile End Hospital, Bancroft Road, London E1 4DG, UK \\ 'Department of Diabetes and Metabolism, The Royal London Hospital, London, UK
}

\section{ABSTRACT}

Background and Objectives: Type 2 diabetes is common amongst Bangladeshis, and prevention strategies are needed. Little is known about the views of younger people concerning diabetes prevention and the risk factors. We aimed to explore the experience and views on the prevention of diabetes amongst young Bangladeshis in Tower Hamlets. Methods: Semistructured interviews involving 40 young Bangladeshis. Results: Participants were aware of diabetes being a major health issue and its link with poor diet. Many had a relative with diabetes, and some had negative experiences, such as suffering poor control, complications, or hypoglycemia. Knowledge of diabetes was predominantly gleaned from school. Many felt that older generations were at higher risk due to lack of exercise and reliance on traditional diets. Participants recognized that the Westernized diets also increased the risk of diabetes. Views on prevention of diabetes were strong, including increasing diabetes awareness in schools, rewards for healthier lifestyles, reducing costs of exercise, reducing advertising of poorly nutritious foods, and tackling the proliferation of fast food outlets. Conclusions: Young Bangladeshi people showed good knowledge of diabetes and its causes and have cogent ideas on its prevention. The views of young people should be considered when developing diabetes prevention strategies at the local and national level.

Key words: diabetes, prevention, Bangladesh, young people

\section{INTRODUCTION}

Bangladeshis form a significant minority ethnic population in the United Kingdom and have a high prevalence of Type 2 diabetes mellitus (T2D) ${ }^{[1]}$. While genetic factors may be important, cultural and environmental factors are likely to be influential causes of diabetes. Only $26 \%$ of Bangladeshis men and $11 \%$ of Bangladeshi women meet the recommended levels of physical activity ${ }^{[2]}$. Dietary intake of fat, salt, and carbohydrates is also high ${ }^{[3]}$. While immigration results in a change in environment, cultural norms may not change, and may cause conflict in a new environment, and views surrounding food intake are one of the most resistant to change in migrant population. Previous work suggests that the Bangladeshi community sees diabetes and degradation of health as a part of aging rather than the result of poor lifestyle $\mathrm{e}^{[4]}$. Indeed, the cultural history of the Bangladeshi diaspora is characterized by the predominance of infectious disease, as opposed to noncommunicable disease, which may lead to the view that illness stems from sources outside of the body. Culture may not only affect willingness to participate in prevention, but may also obscure the understanding of diabetes.

A qualitative study has shown that cultural attitudes to lifestyle can be difficult to overcome. Among South Asian adults, knowledge of the impact of poor lifestyle on health appears to be good, but significant barriers to improving lifestyle are apparent ${ }^{[5]}$. Physical activity is acknowledged as a strategy in preventing diabetes, but what constitutes physical activity varies considerably. In a study in East London, prayer was cited as sufficient 
to sustain health, and discordant views were seen between people who believed exercise was socially and religiously unacceptable and those who thought it was supported by the religious teaching ${ }^{[5]}$. Furthermore, while apparent motivation to prevent diabetes was high, barriers to prevention included social expectation of "special" foods, the wife's role as provider of tasty meals versus guardian of family health, and the desire to exercise versus fear of social disapproval.

Little is known about the cultural and situational risk factors for T2D in younger South Asians. The aim of this study was to develop an understanding of the knowledge and experience of younger Bangladeshis in diabetes and its prevention.

\section{METHODS}

Data was collected during 2014 from youth groups in Tower Hamlets. A total of 40 young people participated. All participants were between the ages of 17 and 25 and resided within Tower Hamlets. All interviews were conducted in English.

Data was collected using semistructured interviews conducted by one researcher (AF). The sessions explored the areas of awareness of the condition and its causes, personal experience of diabetes, how they acquired information about diabetes, their insight into why diabetes is such a problem, and what could be done about it. Data was analyzed by thematic content analysis using the constant comparative method to isolate recurring themes in participant responses to each topic ${ }^{[6]}$. This method involves identifying patterns within qualitative information in order to discover emergent themes. This method can describe the experiences and reality of the participants, and acknowledge the ways in which individuals make meaning of their experiences. Information from interviews was recorded, transcribed, and read in detail by the investigators to code key words, phrases, and associations in order to identify emergent themes. Once themes were established, exemplary quotations were derived, which were chosen for their significance. After 40 interviews, we determined that no new themes were emerging.

\section{RESULTS}

Forty people participated in the interviews, $32(80 \%)$ of whom were male. Thematic analysis showed the emergence of the following themes.

\section{Awareness of the condition}

The majority of the participants had a basic understanding on what diabetes was and, although not all information was accurate, all participants had heard of diabetes and most connected it with healthy living. Diabetes was most often described as having to do with "sugar levels" and "eating too much sugar." While fats and other unhealthy foods were described as the causes, the primary emphasis was on sugar. School biology classes were where they gained the basic knowledge of diabetes. They were quick to stress the limits to what schools taught them about diabetes, suggesting that schools focused more on the biological aspects of diabetes, rather than providing information on prevention or raising awareness on diabetes. Healthy living, however, was more commonly addressed in schools, with some emphasis on care with diet and increasing exercise.

Participants also reported that they gained information about diabetes from friends or family. A few of them commented that information was available from their general practitioner (with the exception of information gained from accompanying a family member with diabetes to a GP appointment) and most seemed to believe that little information was available to the general population.

"...I know that diabetes deals with sugar and eating a lot of sugar although sometimes people can be born with it. Yes, I definitely think. it's a problem especially among Asians who aren't aware about how much sugar they eat. There is sugar in everything."

"I think it is a type of cancer and has to do with low blood sugar..... I know it is caused by your diet and having a bad diet."

"I know it's caused by eating too much sugar and people being overweight."

"Diabetes is caused from having too much sugar in your blood..."

"Diabetes us a disease caused by having too much sugar. I know that there are two different types and that it can be caused by leading an unhealthy lifestyle. It affects your sugar and cholesterol levels."

"I know that diabetes is related to sugar levels and I think that it can kill people..... I think it is caused by having too much sugar."

"I have a basic idea of what diabetes is. I think diabetes is caused by having too much sugar in your food; sugar, salt and oil. It can also be affected by your genes."

"We also talk about it in science class. There is plenty of information on the Internet if people want to look at it but not enough in schools or from doctors."

\section{Understanding of the causes of diabetes}

Genetics was mentioned as a risk factor for diabetes along with obesity and old age. The majority believed that diabetes was a problem among Bangladeshis, highlighting the dietary problems within the community and the availability of cheap fast food. 
"I think that diabetes is a problem in the community because young people don't care what they eat so long it fills them up. At a chicken shop, you get lots of food for very little money."

"Fast food is convenient and cheap and gives you quick energy. Buying unbealthy food saves you the trouble having to ask your mother or sister to cook something healthy."

"I know that diabetes is common in the Bangladeshi community. I know it is caused by unhealthy diet such as too much sugar and high cholesterol foods."

"It's definitely a problem in our community. Sugar is sold everywhere and everyone goes to buy sweets after school. Everything has sugar....."

"We have so much access to sugar and it's so cheap. Kids eat so much candy after school. Everyone goes to buy sweets after school."

"We have Healthy Eating Day and workshops in school that teach bealthy choices. If you participate and are willing to change, you won't be at risk. I don't think I'm at risk."

"I know that diabetes is a bigproblem in the Bangladeshi population. There are a bunch of high risk factors like genetics, weight, and smoking......"

\section{Experience of diabetes within the family}

Thirty-five participants $(87.5 \%)$ had a relative or friend with diabetes. Many participants knew a close family relative with the condition, and were aware of its hereditary nature, and higher risk in people of Bangladeshi origin. Relatives suffering from diabetes were also a source of information. Many said they had to translate for their relatives when visiting doctors.

"T know about diabetes because of my dad. I always go with him to the GP so I can translate for him. I also got a general idea from science class in school, but I don't think that there are many programs for young people on the subject."

"My dad had diabetes, he is getting older. He doesn't have much energy anymore and he gets ill once or twice every month. My mum has diabetes and the GP told her she has to completely change her diet. She is on a bunch of medication and deals with high cholesterol."

"My gran and aunt have diabetes and I learned about diabetes from family members."

"My dad has diabetes and he has to watch his eating habits as well as get injections. It has affected his life because he has many medical problems; sometime he faints on the spot....."

"My dad has diabetes and I know he has issues with his insulin. My mum has diabetes and I know she can't regulate her blood sugar......"

\section{Generational Differences}

Most participants believed that there was a difference between their parents' generation and their own regarding understanding of the risk factors for diabetes. Most believed they were more educated on healthy living than their elders. Participants also believed they exercised more regularly than their parents. Some participants discussed the necessity of having variation in diet, often in connection to the older generation eating only traditional meals of curry and rice, which was viewed negatively. Many participants believed that having too much curry and rice was bad for health. Some suggested a connection between the older generation and inactive lifestyles. For example, many reported that their parents just "stayed in the house". The majority of participants believed that diabetes levels would increase in the future. Some felt the unhealthy eating habits of the younger population as possibly worse than the older generation.

'It is a bigger problem in the older generation because they don't exercise enough and they eat lots of oily food, not healthy food. I think our generation is more aware of the importance of food and exercise......"

"It was definitely a problem in the older generation because they weren't as well educated as us..."

"... I think there is a difference between my generation and my parent's generation. They don't ever vary their diet. They think the rice and curry is best......"

"...It is also a problem that parents don't know the correct foods to feed their children so children eat unhealthy food from a very young age. I think that the older generation exercises much less than the younger generation."

"T think that there is a difference between the older generation and the younger generation. The older generation had no support, information, or help from the local services. They were unaware of healthy lifestyle and ate a very unhealtby cultural diet of only curry and rice."

"Our generation eats much more junk. food than ourparents, but we also exercise more than they do."

\section{Barriers to healthy diet and lifestyle}

Sweets and fried chicken shops were commonly mentioned in regard to unhealthy eating habits. Participants expressed that the need to access cheap, filling, tasty food led to unhealthy food choices. Participants reported that healthy food was expensive and difficult to access, was also more time-consuming to make, did not taste as good, and was not filling. Although most agreed that diabetes was a problem within the community, young people were unlikely to prioritize healthy eating over availability and 
cost. The availability of healthy living activities such as gym facilities and exercise classes was discussed. Many reported that they were less likely to go to the gym because it was expensive.

“.... it's more of a problem in younger kids because sweets are cheap, easy to get, and they taste good. We can't help ourselves. It's like the new tobacco."

'I think it's a problem because people don't really care about it. It's not taken as seriously as cancer since we know people who have it and people don't really die. No one realises it's life threatening."

"People my age eat a lot of fried chicken because it is quick and cheap. Healthy food takes too long to prepare. I also think that it is a problem because no one really advertises for healtby foods. All advertisements are for unhealthy stuff."

"The problem is that there aren't very many options to eat healthy. Many of my friends eat badly because unbealthy food is quick, cheap, and fills you up."

"I think that in the younger population, we have more of an opportunity to avoid diabetes, but it is also harder to avoid because bad food is everywhere and easy to get, and because we have technology which makes us lasy....

"Healtby food is expensive and young people are more likely to spend money on new technology or going out rather than bealthy food. Gym memberships are so expensive as well. Healthy diet just isn't one of the concerns of young people. We are more interested in our social lives."

\section{Suggestions for prevention}

Some participants suggested that initiatives for affordable gym membership would enable people to be more inclined to stay healthy and physically fit. Another suggestion was that information on diabetes was more readily available in schools, through school visits and resources for teaching on diabetes. It was suggested that healthy food needed to be made cheap and tasty to combat the cheap and inexpensive (unhealthy) option of chicken and chips. Economic issues, which prevent young people from opting for healthy living practices, were highlighted. Some participants felt that awareness issue was not an issue, but people needed more help to make the right choices. Advertising of unhealthy foods was highlighted as important to curtail. Improving the quality of school meals was also suggested as important to reduce unhealthy diets.

"I think it needs to be introduced in schools. People have to listen to what is tanght in schools because we are required to be there. There isn't enough awareness surrounding the subject of diabetes."
"At school they teach us about healthy choices and I feel I have a good idea about health. I think that it is a problem because children are lasy and won't get it. For there to be a change, we need posters in the schools and constant encouragement every month so we won't forget about it."

“.....Education should start with the parents to properly teach their kids what to eat. There need to be clubs available that let young people go to the gym for free. In the schools, PE isn't really PE. You don't really get educated or learn how to exercise, you just play games....."

"It would help if there weren't so many advertisements on kids TV. Maybe they should be banned and only advertise bealthy foods. After school fitness activities would belp."

"It would make a difference to give workshops but don't just give talks. Give examples and make sure people know about the really bad effects of diabetes. People aren't motivated to change."

'There are so many advertisements for unbealthy foods on kids' shows. There should be a program on kids' television that talks about diabetes and shows way to eat healtby. They should make something that tastes like sugar but is not bad for you....."

"Maybe target the chicken shops because there are so many."

"I think that the best way to make our generation more aware and willing to change is to make sure that people are forced to learn about diabetes in schools."

"It would be effective to show the extreme effects diabetes can have. If you tell real life stories, people are more likely to listen....."

"......It would be effective to show a video of the effects of diabetes so that people know the terrible things that can happen. It would be beneficial to have free or low cost check-ups available in markets."

'Nothing is tanght in the schools and so people don't know the risks or effects. There definitely isn't enough information out there. This is the first time someone has talked to me about diabetes."

"To make a positive change I think that parents should be educated on what to feed their kids. If you focus on schools and colleges and present the information in a fun way, people might listen. If you friend is doing it, you are more likely to be interested."

"People know about bad foods, but not the extent of how bad they are. No one realizes that sugar is literally in everything. Another way to address bealthy eating would be to focus on making school dinners healthy."

"Unhealthy food is served in schools and this is something that should be much more regulated. I think parents would even be willing to volunteer to cook healthy food for schools. This would create more jobs and encourage bealtby eating." 


\section{DISCUSSION}

South Asians living in the UK are at three to six times at risk for developing T2D compared to white Europeans. In Tower Hamlets, around 18\% of South Asians are considered to be at high risk for developing diabetes ${ }^{[7]}$. In recent years, metabolic syndrome and T2D is becoming more common among South Asian children and adolescents, and ethnic differences in Type 2 DM precursors are apparent in UK children in the first decade of life ${ }^{[8]}$. For the same BMI, South Asians have a higher body fat percentage, abdominal obesity, intramyocellular lipid, and liver fat content in comparison to white Europeans, which contributes to a higher risk of developing insulin resistance, at lesser degrees of adiposity ${ }^{[9]}$.

The aim of our study was to explore the understanding of younger Bangladeshi people on diabetes and its risk factors. The results suggest that many young people have heard of diabetes, are aware of its link with poor diet and physical inactivity, and many of them have cogent views on how the problem could be tackled. Excess intake of sugar and unhealthy fried foods (in particular fried chicken) was widely considered the dominant cause of diabetes, although many younger people felt that the traditional diet of curry and rice in their elders was responsible for their high incidence of diabetes.

Many participants had experience of diabetes among close family relatives. Some of these experiences were around accessing health care, for example acting as a translator for a relative with diabetes. Others described family members' negative experience of diabetes, such as collapsing, developing complications, or taking medications and insulin. Most young people had some information on diabetes from their school curriculum, although this had perhaps only focused on biological models of diabetes, rather than the health effects of the condition.

An interesting finding was the perceived differences seen between young people and their parents or other elders in their knowledge of risk and in eating behaviors. Many young people viewed the traditional diet rather negatively, but recognized that aspects to a Western diet of high sugar and fat intake was equally negative. Many felt they had a better knowledge of diabetes and healthy lifestyles than their elders, but recognized that there were many barriers to improving their lifestyle, particularly with regards to diet and physical activity.

Suggestions to help reduce risk of diabetes among Bangladeshis were both perceptive and recognized the importance of external factors on diabetes risk. The participants recognized that economic factors are paramount in helping people to lead healthier lives. They understood that unhealthy food was cheap and readily available, and that healthy options had to be made both more readily available and more affordable. An interesting suggestion was the use of "incentives" or "rewards" to help people lead healthier lives. This area is controversial, but has been tried successfully in smoking cessation initiatives in pregnancy ${ }^{[10]}$. A more sustained and longer term system of incentives might be more difficult in the area of nutrition, but perhaps more disincentives to eat unhealthy food (through taxation) might be feasible, coupled with subsidies for healthier options ${ }^{[11-12]}$. A number of participants mentioned the ready access to fried chicken shops, especially ones near to schools. One participant described these like "selling drugs to schoolchildren." The local authority is best placed to try and reduce the numbers of such outlets, especially near to schools. School lunches were also mentioned as needing work, as was access to low cost exercise facilities and better education on methods of keeping physically active.

While it was encouraging to hear that many young people had gleaned some knowledge of diabetes from school, it was clear that they felt that this area of education could be enhanced. Teaching more about the potential complications of diabetes was suggested as a possibility, in order to raise awareness among young people of the potentially devastating effects of the condition. In addition, participants felt that hands on workshops to help with knowledge around healthy eating would be helpful.

One study has previously undertaken interviews and questionnaires of Bangladeshi children aged 11-14 living on a council estate to determine factors that led to dietary choices in these children ${ }^{[4]}$. The research found that interwoven cultural and structural pressures encouraged frequent consumption of energy-dense foods. The children were exposed to increased availability and affordability of energy-dense foods, along with cultural pressures of being the adolescent children of immigrants from Bangladesh, living in economically deprived areas.

In our review of the literature, we were unable to find many studies examining views and experiences of Type $2 \mathrm{DM}$ in young people. One previous report of younger family members of Hispanic patients with diabetes showed a number of influences on intergenerational legacy of diabetes including food preparation within the family, participation of physical activity within the family, expectations for the future and understandings of diabetes being shaped by family members, well-intentioned actions have negative consequences, and children and parents supporting each other's diabetes care ${ }^{[13]}$. Our research is the first, to our knowledge, to report on knowledge, 
experience, and views of young Bangladeshis on the topic of diabetes, and its prevention. In our survey, we found that young people have good knowledge of diabetes, are interested in knowing more, and have helpful suggestions in how to help prevent diabetes. It is important that such views are heard when working toward improving diabetes prevention strategies in high-risk communities.

\section{Informed Consent Statement}

All individuals participating in the study gave the full informed verbal consent.

\section{Conflict of Interest}

None of the authors have any conflicts of interest.

\section{REFERENCES}

1. Chowdhury MA, Uddin MJ, Khan HM, Haque MR. Type 2 diabetes and its correlates among adults in Bangladesh: a population based study.BMC Public Health 2015;15:1070.

2. British Heart Foundation. Coronary Heart Disease statistics 2012. Available from: https://www.bhf.org.uk/publications/statistics/coronaryheart-disease-statistics-2012. Accessed on May 20, 2016.

3. Lofink HE. 'The worst of the Bangladeshi and the worst of the British': exploring eating patterns and practices among British Bangladeshi adolescents in east London.Ethn Health 2012;17:385-401.

4. Greenhalgh T, Helman C, Chowdhury AM. Health beliefs and folk models of diabetes in British Bangladeshis: a qualitative study.BMJ 1998;316:978-83.
5. Grace C, Begum R, Subhani S, Kopelman P, Greenhalgh T. Prevention of type 2 diabetes in British Bangladeshis: qualitative study of community, religious, and professional perspectives.BMJ2008;337:a1931.

6. Vaismoradi M, Turunen H, Bondas T. Content analysis and thematic analysis: Implications for conducting a qualitative descriptive study. Nursing \& Health Sciences 2013;15:398-405.

7. Mathur R, Noble D, Smith D, Greenhalgh T, Robson J. Quantifying the risk of type 2 diabetes in East London using the QDScore: a crosssectional analysis.Br J Gen Pract 2012;62:e663-70.

8. Thomas C, Nightingale CM, Donin AS, Rudnicka AR, Owen CG, Sat$\operatorname{tar}$ N, Cook DG, Whincup PH. Socio-economic position and type 2 diabetes risk factors: patterns in UK children of South Asian, black African-Caribbean and white European origin.PLoS One 2012;7:e32619.

9. Whincup PH, Nightingale CM, Owen CG et al. (2010). Early Emergence of Ethnic Differences in Type 2 Diabetes Precursors in the UK: The Child Heart and Health Study in England (CHASE Study). PLoS Medicine 2010;7:e1000263

10. Tappin D, Bauld L, Purves D, Boyd K, Sinclair L, MacAskill S, et al. Cessation in Pregnancy Incentives Trial Team. Financial incentives for smoking cessation in pregnancy: randomised controlled trial. BMJ 2015;350:h134.

11. Wegman MP (2015). Taxes and subsidies to improve diet. JAMA 2015;313:307-8

12. Arantxa Colchero M, Popkin BM, Rivera JA, Ng SW. Beverage purchases from stores in Mexico under the excise tax on sugar sweetened beverages: observational study. BMJ 2016;352:h6704

13. Pyatak EA, Florindez D, Peters AL, Weigensberg MJ. "We are all gonna get diabetic these days": the impact of a living legacy of type 2 diabetes on Hispanic young adults' diabetes care. Diabetes Educ 2014;40:648-58.

How to cite this article: Choudhury SR, Furbish A, Chowdhury TA. Prevention of diabetes in Bangladeshis in East London: Experiences and views of young people. J Transl Intern Med 2016; 4: 88-93. 